\title{
How to Established National Occupational Health and Safety at Institute
}

\author{
Almasoud $\mathbf{M}^{*}$ \\ Occupational Medicine, Saudi Arabia
}

*Corresponding author: Mansoor Almasoud, Occupational Medicine, Riyadh-13316-7933, UNIT No:1, Saudi Arabia, Tel: 00966505207434; Email: mns987@yahoo.com

\section{Commentary}

Volume 4 Issue 4

Received Date: July 07, 2020

Published Date: August 10, 2020

DOI: $10.23880 /$ eoij-16000251

\section{Commentary}

It is the health care services primarily concerned with maintaining the health of people at work or those who were at one time injured or exposed to a hazard while on the job , Its principal role is the provision of health advice to organizations and individuals to ensure that the highest standards of Health and Safety at Work can be achieved and maintained (should be made up of multidisciplinary teams whose composition should be determined by the nature of the duties to be performed).

The field of occupational health and safety presents a large variety of job opportunities for those who are interested in promoting workplace health and safety. Broadly speaking, occupational health and safety workers are responsible for maintaining a safe working environment. In the public sector, health and safety workers primarily enforce health and safety legislation, and in the private sector, they primarily focus on risk management, employee productivity, and reduction of liability.

Form my field of specialty and due to the limitation and shortage, we face it during collecting the data in this workshop so, we suggest and recommend the following

1. Create a national OHS system

2. Improve our reporting and recording system

3. Create National institute OSH (Safe Work) systems, to promote our national management system, improve working conditions.

\section{Why we need OSH system?}

Looking for and comparing the developing countries vs industrial countries we found

- Absence of OSH at the level of the undertakings in MOST of these countries.
- A national OSH program might not even exist.

- OSH in developing countries, when present, similar to those during industrialization in the 19th century.

- Specialists in the field: either not present or few.

\section{Moreover, we need to:}

- Introduce/strengthen/enforce Preventive measures.

- Strengthen: IDENTIFICATION procedures /RECORDING procedures and/NOTIFICATION procedures for occupational diseases and accidents so that we

- Identifying their causes

- Establishing preventive measures

- PROMOTING THE HARMONIZATION OF RECORDING AND NOTIFICATION SYSTEMS and

- Improving the compensation process

\section{OSH Program (safe work) overall Aim to (ILO.Ref.)}

a. Creating awareness of the dimensions and consequences of work-related accidents, injuries and diseases,

b. Promoting the goal of basic protection for all workers in conformity with international labor standards

c. Enhancing the capacity of country and industry to design and implement effective preventive and protective policies and programs.

So, create and establishing a new national agency with duty of OSH taking care of all occupational related activities including

- Occupational registry

- Implementation of all ILO conventions and recommendations signed by our country

- Occupational health services

- Training and education 


\section{National Institution for OSH Responsible(in Addition to Training and Education)}

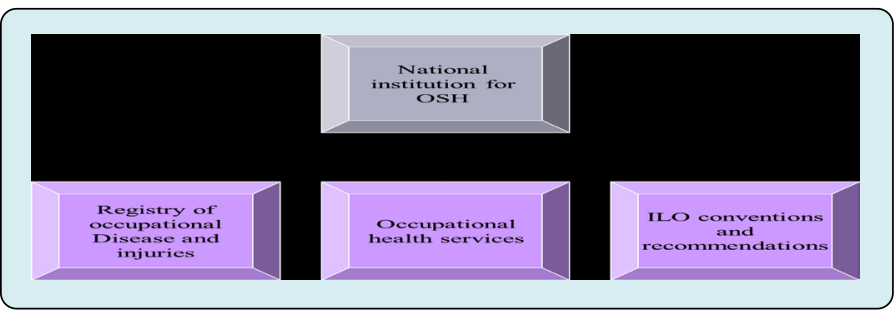

Who is Responsible about the Application of the National Institution for OSH (model)?

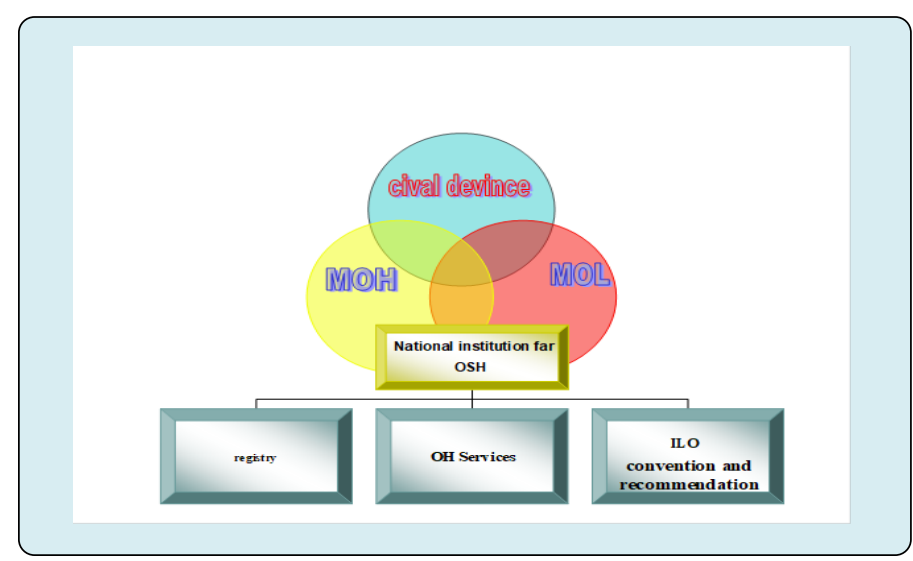

At the National Level:

I. Ministry of Health MOH?'

II. Ministry of labor MOL?

III. Civil defense?

All three have roles to play. It is a three-pronged approach, to create alliance and partnership between the three, with the objective of developing a sustainable safety culture in the workplace.

$>$ Suggested Examples of Roles:

I. M.O.H. (Within Their Jurisdiction)

- Establish standards and codes of practice

- Establish a national framework for occupational health and safety at factory levels

- Design a sound reporting system for occupational diseases and accidents.

- Conduct research and analysis of reports

- Education on occupational health and safety to management

- Publishing and periodically reviewing updates of standards and guidelines

- Training of factory physicians in collaboration with academic institutes in the field of $\mathrm{OSH}$

- $\quad$ Liaise between industry and WHO/ILO

II. Civil Defense (Within Their Jurisdiction)

- $\quad$ Enterprise inspection: strengthen and enforce their role:

- Guidance

- Inspection

- Powers to take action

- Education on occupational safety

- Rapid response capacity in case of disasters (God forbid)

III. Ministry of Labor (Labor Office) (Within Their Jurisdiction)

- Factory inspection: strengthen and enforce the capacity of labor inspectors.

- Guidance

- Inspection

- Powers to take action

- Health education on occupational safety and health.

- Maintain a record of enterprises with good and those with bad safety records.

- Encourage industry to adopt "safe work " policy and include a reward system.

- Training for factories' safety officers when these are available

\section{Challenges \& Limitations}

- Absence of OSH program at the level of the undertakings in MOST of these developing countries

- Concentration more toward curative medicine than preventive

- Conceptually, employers, investors, workers and decision-makers do not yet appreciate the real roles of occupational health services

- $\quad$ Employers consider prevention of work-related diseases and accidents, improvement of working conditions, and enforcement of standards as a cost to business.

- A major challenge is how to make occupational health services attractive to the employers

- No or less study and researches done in the felid

- Week infra structure and basic data

- how to address environmental health issues

- $\quad$ The central challenge to occupational health and safety practitioners is to convey understanding of the real benefits of occupational health services to all parties concerned

- Major challenge ( Geographic, economic, administrative and social) 